\title{
Acute hypoxemia in a parturient with primary ciliary dyskinesia following the administration of intravenous oxytocin: a case report
}

\section{Hypoxémie aiguë chez une parturiente ayant une dyskinésie ciliaire primitive après l'administration intraveineuse d'ocytocine: une étude de cas}

\author{
Amar Nandhakumar, MD • Gregory L. Silverman, MD \\ Received: 25 July 2013/Accepted: 20 September 2013/Published online: 3 October 2013 \\ (C) Canadian Anesthesiologists' Society 2013
}

\begin{abstract}
Purpose We present the case of a parturient diagnosed with primary ciliary dyskinesia with secondary bronchiectasis who developed significant hypoxemia following administration of intravenous oxytocin during Cesarean delivery under spinal anesthesia. This case suggests that oxytocin can affect pulmonary vascular tone and interfere with the protective effects of hypoxic vasoconstriction.

Clinical features A 35-yr-old primigravida at 37 weeks gestation presented for a scheduled Cesarean delivery due to breech positioning and fetal abnormalities. The patient had a diagnosis of primary ciliary dyskinesia and had undergone a right middle lobectomy seven years earlier for resultant bronchiectasis. Pulmonary function testing in the month prior to delivery showed a $4 \%$ decline in her baseline FEV to $1.06 \mathrm{~L}$ (32\% of predicted value) but she was functionally well. The patient initially had an uneventful spinal anesthetic and maintained an oxygen
\end{abstract}

\footnotetext{
Author contributions The authors of this manuscript contributed equally to its preparation and submission. Amar Nandhakumar researched and wrote the initial draft with Gregory L. Silverman providing subsequent revisions to the text and adding the discussion section. Both Amar Nandhakumar and Gregory L. Silverman edited the final submission.
}

\footnotetext{
A. Nandhakumar, MD

Department of Anesthesia, Kovai Medical Centre and Hospital, Coimbatore, India

G. L. Silverman, MD ( $₫)$

Department of Anesthesia and Pain Management, Mount Sinai Hospital, University of Toronto, 600 University Ave, Toronto, ON M5G 1X5, Canada

e-mail: gsilverman@mtsinai.on.ca
}

saturation of $97 \%$ on room air in the supine position until delivery of her baby. An intravenous infusion of oxytocin for uterine contraction was started following removal of the placenta. The patient then became acutely hypoxemic with a drop in room air saturation to $84 \%$ but with no other accompanying hemodynamic instability. Maternal oxygen saturation did not improve with the addition of supplemental oxygen, and the patient had a significant arterial-alveolar oxygen gradient suggesting an intrapulmonary shunt. No supporting clinical, radiologic, or laboratory evidence of a thrombotic, air, or amniotic fluid embolism or mucous plug was detected. The patient remained hypoxemic during the postoperative period with gradual improvement back to baseline saturation in approximately $48 \mathrm{hr}$.

Conclusion The vasodilatory effects of intravenous oxytocin on the pulmonary vasculature may worsen shunting and interfere with hypoxic pulmonary vasoconstriction, producing clinically significant hypoxemia in patients with comorbid lung disease. Oxytocin should be used with caution in patients with compromised lung function.

Résumé

Objectif Nous présentons le cas d'une parturiente ayant un diagnostic de dyskinésie ciliaire primitive avec bronchiectasie secondaire qui a développé une hypoxémie significative après l'administration intraveineuse d'ocytocine au cours d'un accouchement par césarienne sous rachianesthésie. Ce cas suggère que l'ocytocine peut affecter le tonus vasculaire pulmonaire et bloquer avec les effets protecteurs de la vasoconstriction hypoxique.

Caractéristiques cliniques Une femme primigeste de 35 ans à 37 semaines de grossesse s'est présentée pour un 
accouchement planifié par césarienne en raison d'une présentation du siège et d'anomalies fretales. Une dyskinésie ciliaire primitive avait été diagnostiquée chez cette patiente qui avait subi une résection du lobe moyen du poumon droit plusieurs années auparavant en raison d'une bronchiectasie secondaire. Les épreuves fonctionnelles respiratoires réalisées dans le mois précédant l'accouchement avaient montré une baisse de $4 \%$ de son VEMS basal à 1,06 L (32\% de la valeur théorique) mais elle allait bien sur le plan fonctionnel. La rachianesthésie initiale de la patiente s'était déroulée sans incident particulier et la saturation en oxygène s'était maintenue à $97 \%$ en air ambiant, la patiente étant en décubitus dorsal jusqu'à la naissance de son bébé. Une perfusion intraveineuse d'ocytocine destinée à la contraction utérine a été débutée après l'extraction du placenta. La patiente est alors devenue subitement hypoxémique avec une chute de la saturation à l'air ambiant à $84 \%$, mais sans aucun autre signe d'instabilité hémodynamique. Un apport supplémentaire d'oxygène n'a pas amélioré la saturation en oxygène de la mère qui a présenté un gradient d'oxygène artériolo-alvéolaire suggérant un shunt intrapulmonaire. Aucune donnée probante clinique, radiologique ou biologique, en faveur d'un événement thrombotique, d'une embolie gazeuse ou de liquide amniotique, ou d'un bouchon muqueux n'a été détectée. La patiente est restée hypoxémique pendant la phase postopératoire puis a présenté une amélioration progressive avec un retour à la saturation de base en approximativement 48 heures.

Conclusion Les effets vasodilatateurs de l'ocytocine intraveineuse sur la vascularisation pulmonaire peuvent aggraver un shunt et empêcher une vasoconstriction pulmonaire hypoxique, provoquant une hypoxémie cliniquement significative chez des patientes ayant une comorbidité pulmonaire. L'ocytocine doit être utilisée avec prudence chez les patientes ayant une atteinte de la fonction pulmonaire.

Primary ciliary dyskinesia (PCD) is a genetically heterogeneous recessive disorder whose cardinal feature is dysmotile cilia with the development of progressive respiratory disease. The development of PCD has been linked to a number of different genes associated with ciliary biogenesis and function, and the estimated incidence of PCD in the general population is approximately one in 10,000-20,000 births. Symptoms begin in infancy and may initially be benign (e.g., chronic wet cough, nasal congestion, and sinus infections), leading to missed or improper diagnoses. The condition invariably progresses to chronic recurrent respiratory infections and bronchiectasis in adulthood. When accompanied by heterotaxy or situs inversus, PCD is referred to as Kartagener syndrome. In addition to pulmonary disease, fertility problems are nearly universal in patients with PCD; sperm are dysmotile in men, while women have impaired ciliary function in the fallopian tubes predisposing them to reduced fecundity or ectopic pregnancy. ${ }^{1}$ A search of the medical literature does not detail any specific pregnancy or labour-related complications with PCD other than those associated with ectopic pregnancy, and descriptions are lacking regarding appropriate management of PCD patients in labour.

The patient provided informed written consent for the preparation and submission of this case report.

\section{Case report}

A 35-yr-old primigravida at 37 weeks gestation with a diagnosis of PCD underwent a planned Cesarean delivery for breech presentation, fetal ventriculomegaly, and restriction of intrauterine growth. The diagnosis of PCD without heterotaxy was confirmed by genetic testing. The patient had a right middle lobectomy for bronchiectasis secondary to PCD in 2006 at age 29. Pulmonary function testing during pregnancy showed a gradual decline from her baseline $\mathrm{FEV}_{1}$ of $1.25 \mathrm{~L}$ ( $36 \%$ of predicted value) to a value of $1.06 \mathrm{~L}$ ( $32 \%$ of predicted value) at 36 weeks. Her functional status remained good throughout the pregnancy, and she was able to carry out her activities of daily living without restriction and sleep in a recumbent position. She also suffered from asthma and recurrent episodes of pneumonia, and her respiratory tract was chronically colonized with Pseudomonas.

The patient's other medical history included hypothyroidism, gastroesophageal reflux disease, and infertility; the current pregnancy was the result of in vitro fertilization. Her surgical history was significant for her lobectomy and several laparoscopic surgeries for endometriosis, all of which involved uneventful general anesthesia. Her medications at the time of surgery were 1-thyroxin $125 \mu \mathrm{g} \mathrm{od}$, omeprazole $40 \mathrm{mg}$ od, inhaled salmeterol and fluticasone, and nebulizations of azithromycin, salbutamol, and tobramycin. She was noted to be allergic to shellfish and latex, which caused urticaria, and she was intolerant of acetaminophen.

On examination, she was $165 \mathrm{~cm}$ tall and weighed $66 \mathrm{~kg}$. She appeared generally healthy with no apparent distress. Her admission vital signs on the day of delivery showed sinus rhythm at a rate of 92 beats. $\mathrm{min}^{-1}$, blood pressure of $130 / 80 \mathrm{mmHg}$, and a room air saturation of 97\%. There was no cyanosis or clubbing. Heart sounds were normal to auscultation, and she had bibasilar coarse 
leathery crepitations. Her admission hemoglobin was $118 \mathrm{~g} \cdot \mathrm{L}^{-1}$.

The patient gave her consent for Cesarean delivery under spinal anesthesia, and standard monitoring was established with pulse oximetry, noninvasive blood pressure, and electrocardiography. Spinal anesthetic was performed in the sitting position under strict asepsis with $0.75 \%$ hyperbaric bupivacaine $1.8 \mathrm{~mL}$, preservative-free morphine $100 \mu \mathrm{g}$, and fentanyl $10 \mu \mathrm{g}$. Anesthetic level was obtained bilaterally to T5 and assessed by loss of sensation to touch. Blood pressure was maintained at baseline using intermittent intravenous boluses of phenylephrine, and $650 \mu \mathrm{g}$ in total were administered throughout the course of the operation. After supine positioning with a right hip wedge for uterine displacement and initiation of surgery, the patient's oxygen saturation continued at $96-98 \%$ on room air. The baby was delivered 30 min post-spinal, and an intravenous infusion of oxytocin 20 units. $\mathrm{L}^{-1}$ at a rate of approximately 0.3 units $\cdot \mathrm{min}^{-1}$ was started to achieve uterine contraction. The patient received 20 units over the first hour following delivery of the placenta. Prophylactic ondansetron $4 \mathrm{mg} i v$ was also administered.

Within a minute of initiating the oxytocin infusion, the patient's oxygen saturation dropped from $95 \%$ to a nadir of $84 \%$. No change in heart rate or blood pressure was observed, and the patient was otherwise clinically comfortable reporting no subjective symptoms of respiratory distress. The oxygen saturation stayed within the range of $84-88 \%$ despite elevating the head of the bed, performing alveolar recruitment maneuvers, and providing supplemental oxygen by face mask at a rate of $10 \mathrm{~L} \cdot \mathrm{min}^{-1}$. An arterial blood gas (ABG) done within minutes of the initial desaturation event showed a $\mathrm{pH}=7.39$, $\mathrm{pCO}_{2}=35 \mathrm{mmHg}, \mathrm{PaO}_{2}$ of $51 \mathrm{mmHg}, \mathrm{S}_{\mathrm{a}} \mathrm{O}_{2}$ of $87 \%$, and serum bicarbonate $=21 \mathrm{mmol} \cdot \mathrm{L}^{-1}$. The surgeons proceeded with closure and the patient was brought to the recovery area in stable fashion with the exception of her persistent hypoxia.

The oxytocin infusion rate was gradually reduced and the patient received an additional 20 units of oxytocin over the six hours following completion of the operation. The patient was positioned with her head elevated at a $45^{\circ}$ angle. An ABG was repeated after two hours of supplemental oxygen by face mask, revealing an improvement in oxygen saturation to $97 \%$ but continued presence of a significant reduction in $\mathrm{PaO}_{2}$ to $78 \mathrm{mmHg}$. The calculated arterial-alveolar $\mathrm{PO}_{2}$ gradient was $228.5 \mathrm{mmHg}$. An electrocardiogram done in the recovery room showed sinus tachycardia at a rate of 115 beats. $\min ^{-1}$ with no other abnormal features. Supplemental oxygen was gradually tapered, but the patient had a repeat $\mathrm{ABG}$ four hours postoperatively showing a $\mathrm{PaO}_{2}$ of $65 \mathrm{mmHg}$ and $\mathrm{SpO}_{2}$ of $88 \%$ on room air. Supplemental oxygen by nasal prongs at a rate of $3 \mathrm{~L} \cdot \mathrm{min}^{-1}$ was restarted for the next $12 \mathrm{hr}$, and her $\mathrm{SpO}_{2}$ was maintained at $93 \%$. The patient was maintained on the standard institutional infusion of intravenous oxytocin to prevent postpartum uterine atony while other diagnoses were being investigated. Sixty units of oxytocin were infused over approximately $20 \mathrm{hr}$, including the oxytocin received during the course of her surgery.

The patient was hemodynamically stable throughout her surgery and recovery period. Postoperative laboratory investigations showed a hemoglobin $=114 \mathrm{~g} \cdot \mathrm{L}^{-1}$, prothrombin time $=9.6 \mathrm{sec}$, international normalized ratio $=0.9$, activated partial thromboplastin time $=$ $25.4 \mathrm{sec}$, and serum creatinine $65 \mathrm{mmol} \cdot \mathrm{L}^{-1}$. On the first postoperative day, a computerized tomography scan of her chest with intravenous contrast confirmed the findings of bibasilar bronchiectasis with a small area of pre-existing right-sided lung consolidation, but the tomography failed to detect evidence of an acute pulmonary embolism or mucus plug. The patient was able to maintain an oxygen saturation of $94 \%$ on room air after approximately $20 \mathrm{hr}$. She was discharged on the third postoperative day without prolonged hospitalization or any further complications.

\section{Discussion}

The differential for hypoxemia includes the broad categories of hypoventilation, decreased $\mathrm{F}_{1} \mathrm{O}_{2}$, ventilationperfusion mismatching, shunt, and alveolar diffusion abnormalities. When considering acute hypoxia in the pregnant patient, the differential diagnosis should give special attention to the possibility of a pulmonary embolism, given the relatively hypercoagulable state of pregnancy, as well as an amniotic fluid embolism (AFE) or venous air embolism once the uterus is incised and the maternal vasculature is exposed to the external environment. All these embolic phenomena occur with a variable degree of hemodynamic instability, specifically tachycardia and hypotension. Hypoxemia from an AFE is thought to be the result of an anaphylactoid response producing acute pulmonary artery spasm with concomitant right heart failure; there is also a subsequent hemorrhagic phase with disseminated intravascular coagulation. Venous air embolisms are frequently accompanied by arrhythmias and decreased cardiac output with decreased $\mathrm{pCO}_{2}$. Our patient remained hemodynamically stable throughout the intra- and postoperative period with no acute radiologic or laboratory abnormalities besides her reduced $\mathrm{PaO}_{2}$ and oxygen saturation, making these embolic diagnoses unlikely in the case presented here.

Pregnant patients will also have a reduction in the functional residual capacity of their lungs from the gravid 
uterus, which can be further exacerbated by supine positioning. A high neuraxial block with motor weakness of the respiratory accessory muscles may further contribute to hypoxemia due to hypoventilation. These explanations are unlikely to account for the acute, profound and prolonged hypoxemia seen in this patient. Given the pulmonary comorbidities in this particular patient, an acute massive mucous plug of the proximal brachial tree was considered; however, postoperative imaging did not support this diagnosis. The persistence of arterial hypoxia, despite the addition of increased inhaled oxygen concentration and alveolar recruitment maneuvers, suggests a diagnosis of intrapulmonary shunt.

Hypoxic pulmonary vasoconstriction is a normal physiologic response to maintain blood oxygen concentration and minimize the effects of shunting under conditions where ventilation is impaired, e.g., bronchiectasis, cystic fibrosis, and emphysema. Pulmonary arteriolar pre-capillary smooth muscles close to the acinus respond to hypoxia by contracting, thereby diverting blood flow to areas with better ventilation. Impairment of this response results in the excessive perfusion of non-ventilated alveoli and produces arterial hypoxia. ${ }^{2}$

Given the sudden onset of this event immediately following the administration of intravenous oxytocin the most likely explanation for this patient's hypoxemia, in our view, is oxytocin-mediated pulmonary vasodilation with increased flow to poorly ventilated alveoli and exacerbation of pulmonary shunting. This same phenomenon of increased intrapulmonary shunting and decreased maternal oxygen saturation has been previously described for the uterotonic agent 15-methyl prostaglandin F2-alpha. ${ }^{3} \mathrm{~A}$ decrease in maternal oxygen saturation of approximately $1 \%$ has also been described after elective Cesarean delivery in patients given either intravenous oxytocin or intramuscular 15-methyl prostaglandin F2-alpha. ${ }^{4}$

There is a paucity of human studies specifically examining the specific effects of oxytocin on hypoxic pulmonary vasoconstriction; however, experimental models in rats have shown that oxytocin acts through $\mathrm{V}_{1}$ receptors at the pre-constricted pulmonary vasculature and results in pulmonary vasodilation. ${ }^{5}$ Human studies have shown an oxytocin-mediated decrease in pulmonary vascular resistance of approximately $44 \%$ following intravenous bolus administration of 10 units in healthy parturients in their first trimester. ${ }^{6}$ The vasodilatory effect of the $V_{1}$ agonist, vasopressin, is enhanced in chronically hypoxic rat models, and our case suggests this is also true for oxytocin and its effects on the vasculature of chronically hypoxic human lungs. ${ }^{7}$ Oxytocin may act in a dose-dependent manner through the $\mathrm{V}_{1}$ receptor to diminish the protective effects of hypoxic pulmonary vasoconstriction and produce clinically significant hypoxemic hypoxia.
Another case report of a parturient with Kartagener syndrome, but with a better predicted $\mathrm{FEV}_{1}$ of $65 \%$, makes incidental mention of a desaturation event following the Cesarean delivery of twins but attributes this event to hypotension secondary to spinal anesthesia. There is insufficient detail in the report to make a conclusive diagnosis, but the desaturation seems to correlate with the administration of intravenous oxytocin and resembles the event described here. ${ }^{8}$ Ours is a novel case report explicitly implicating intravenous oxytocin administration as the cause of hypoxemia.

Caution should be exercised when administering oxytocin to patients with severe underlying respiratory disease to minimize the chances of an acute and precipitous drop in maternal oxygen saturation from intrapulmonary shunting. The use of intravenous oxytocin or other uterotonics should be considered early in the differential diagnosis for acute hypoxemia in patients with comorbid respiratory disease. Furthermore, it should be discontinued if the hypoxemia is persistent and not obviously attributable to another diagnosis, and if there is a low risk of postpartum hemorrhage secondary to uterine atony.

Acknowledgements The authors gratefully acknowledge Drs. Mrinal Balki and Alison Macarthur for their valuable insights on the pharmacology of oxytocin and the case discussion.

Conflicts of interest None declared.

\section{References}

1. Knowles MR, Daniels LA, Davis SD, Zariwala MA, Leigh MW. Primary ciliary dyskinesia: recent advances in diagnostics, genetics, and characterization of clinical disease. Amer J Resp Crit Care Med 2013. DOI:10.1164/rccm.201301-0059CI.

2. Swenson ER. Hypoxic pulmonary vasoconstriction. High Alt Med Biol 2013; 14: 101-10.

3. Hankins GDV, Berryman GK, Scott RT, Hood D. Maternal arterial desaturation with 15-methyl prostaglandin F2 alpha for uterine atony. Obstet Gynecol 1988; 72: 367-70.

4. Chou MM, MacKenzie IZ. A prospective, double-blind, randomized comparison of prophylactic intramyometrial 15-methyl prostaglandin F2-alpha, 125 micrograms, and intravenous oxytocin, 20 units, for the control of blood loss at elective cesarean section. Am J Obstet Gynecol 1994; 171: 1356-60.

5. Russ RD, Resta TC, Walker BR. Pulmonary vasodilatory response to neurohypophyseal peptides in the rat. J Appl Physiol 1992; 73: 473-8.

6. Secher NJ, Arnsbo P, Wallin L. Haemodynamic effects of oxytocin (syntocinon) and methyl ergometrine (methergin) on the systemic and pulmonary circulations of pregnant anaesthetized women. Acta Obstet Gynecol Scand 1978; 57: 97-103.

7. Eichinger MR, Walker BR. Enhanced pulmonary arterial dilation to arginine-vasopressin in chronically hypoxic rats. Amer J Physiol Heart Circ Physiol 1994; 267: 2413-9.

8. Gavai M, Hupuczi P, Berkes E, et al. Spinal anesthesia in a woman with Kartagener's syndrome and a twin pregnancy. Int $\mathbf{J}$ Obstet Anesth 2007; 16: 284-7. 